\title{
Physicochemical changes during strawberry development in the field compared with those that occur in harvested fruit during storage
}

\author{
M Cecilia N Nunes, ${ }^{1{ }^{* \dagger}}$ Jeffrey K Brecht, ${ }^{2}$ Alcina MMB Morais ${ }^{1}$ and Steven A Sargent ${ }^{2}$ \\ ${ }^{1}$ Escola Superior de Biotecnologia, Universidade Católica Portuguesa, Rua Dr António Bernardino de Almeida, 4200 Porto, Portugal \\ ${ }^{2}$ Horticultural Sciences Department, University of Florida, IFAS, Gainesville, FL 32611-0690, USA
}

\begin{abstract}
Chandler', 'Oso Grande' and 'Sweet Charlie' strawberry cultivars were harvested at four stages of color development ranging from color break to full red and stored in the dark for 8 days at $1^{\circ} \mathrm{C}$. Changes in the physical and chemical characteristics of fruit during storage were compared with those occurring during development in the field. Strawberry fruit harvested at the three-quarters colored and full red stages continued their development and ripening during storage. However, fruit harvested at the color break and half-colored stages did not develop like those ripened in the field. Strawberries harvested at the three-quarters colored stage developed the same $\mathrm{pH}$, acidity, soluble solids, ascorbic acid and total phenolics content during storage as the at-harvest levels present in strawberries harvested at the full red stage. In addition, three-quarters colored strawberries were as firm and red after storage as the full red stage fruit were at the time of harvest. Thus, strawberries harvested at the three-quarters colored stage can be stored for a longer period than strawberries harvested full red while retaining better color and firmness.
\end{abstract}

Keywords: Fragaria $\times$ ananassa; color; firmness; acids; soluble solids; anthocyanins; phenolics, ascorbic acid

\section{INTRODUCTION}

Strawberry has been classified as a non-climacteric fruit, exhibiting no increase in respiration rate or ethylene production during ripening. ${ }^{1}$ This was confirmed by Perkins-Veazie et al. ${ }^{2}$ who reported that strawberries harvested at the white stage of development and maintained in vitro $\left(88 \mathrm{mmol} \mathrm{L}^{-1}\right.$ sucrose, $1 \mathrm{mmol} \mathrm{L}^{-1}$ hydroxyquinoline sulfate) showed no response during 8 days of continuous propylene exposure in terms of color or autocatalytic ethylene production. However, Luo and $\mathrm{Liu}^{3}$ reported that ethylene might be involved in the ripening of strawberry since their results indicated that at the molecular level ethylene is responsible for promoting some characteristics associated with strawberry fruit ripening, such as softening. Reports from other studies have also suggested that exogenous ethylene exposure during storage of strawberries promotes tissue senescence, as evidenced by tissue collapse, color changes to a translucent dark red and premature browning and shriveling of the calyx. ${ }^{4,5}$ In addition, postharvest color changes in three-quarters colored and full red strawberries have led some authors to suggest that strawberry might be a climacteric rather than an absolute non-climacteric fruit. ${ }^{6,7} \mathrm{~A}$ comparison of ethylene feedback mechanisms in strawberry and tomato suggested that a negative ethylene feedback mechanism may be the reason for the nonclimacteric behavior of strawberry fruit and immature tomato fruit, while a positive ethylene feedback mechanism is the reason for the transition of mature tomato fruit to climacteric behavior during ripening initiation and development. ${ }^{8}$

Non-climacteric fruit are generally harvested fully ripe since it has been considered, especially for strawberries, that ripening does not continue normally following detachment. ${ }^{9}$ However, several studies have shown that, even when harvested at early stages of color development, strawberries can change color during storage. ${ }^{10-14}$ Kalt et al. ${ }^{11}$ reported that, although white strawberries become red during storage, they do not undergo sufficient changes in sugar and acid content to be suitable for fresh consumption. Woodward ${ }^{15}$, in a study using strawberries at different stages of maturity, suggested

* Correspondence to: M Cecilia N Nunes, Food Science and Human Nutrition Department, University of Florida, IFAS, PO BOX 110370, Gainesville, FL 32611-0370, USA

E-mail: cnunes@ifas.ufl.edu

†Present address: Food Science and Human Nutrition Department, University of Florida-IFAS, POB 110370, Gainesville, FL 326110370, USA.

Contract/grant sponsor: JNICT, Portugal 
that the fruit must be harvested immediately after the white stage in order to develop color after harvest similar to commercially ripe fruit. Although the physical and/or chemical changes in harvested strawberries during storage have been the subject of several other studies, only the storage effects on completely white or fully colored strawberries were considered and those studies did not include comparisons with the changes occurring in fruit ripening on the plant. ${ }^{11,12,16-18}$ Miszczak et al. ${ }^{13}$ used strawberries harvested at white, pink and red stages of development, but stored them at $15^{\circ} \mathrm{C}$, a temperature considered to be higher than the optimum for strawberries. Forney et al. ${ }^{14}$ stored $50 \%$ red and full red strawberries at $1^{\circ} \mathrm{C}$, but gave no information on the quality of other maturity stages. In a more recent work, Olsson et al. ${ }^{19}$ studied the effects of harvest year, cultivar, ripeness stage and cold storage on the antioxidant content, total antioxidant capacity and low molecular weight carbohydrates of strawberries. However, in addition to no physical quality factors being measured, those authors evaluated the effects of storage at $4{ }^{\circ} \mathrm{C}$ on white-green vs fully ripe fruit only. Conversely, many other studies have been conducted on the development of strawberry on the plant using several different stages of development, but none of those workers considered the postharvest behavior of the fruit at those different stages. ${ }^{15,20-30}$

The objective of this study was to evaluate the effect of storage at $1^{\circ} \mathrm{C}$, which is considered the optimum temperature for storage of strawberries, on the changes in some physical and chemical characteristics of fruit harvested at four stages of color development, from showing color to full color, and to compare the postharvest physical and chemical changes with those changes occurring during development in the field.

\section{MATERIALS AND METHODS}

\section{Plant material and storage conditions}

'Sweet Charlie', 'Oso Grande' and 'Chandler', strawberries were obtained from a commercial operation near Floral City (FL, USA). The strawberries were grown in double rows on raised beds covered with black plastic mulch, with drip irrigation and fertilization practices according to standard recommendations for strawberry production in Florida. ${ }^{31}$ The strawberries were harvested at four different stages of color development: color break (CB), half-colored (HC), three-quarters colored (TQC) and full red color (FRC) based on the first appearance and subsequent development of red color on the fruit surface. A total of three harvests/experiments were conducted.

Fruit were harvested and removed from the field with minimal delay after harvest and transported from Floral City to the Postharvest Laboratory in Gainesville within approximately $2 \mathrm{~h}$. Eighty strawberries for each color stage, or a total of 240 fruit per cultivar, were selected for uniformity of color development and freedom from defects. Half of the fruit were used for initial physicochemical measurements and half were stored in the dark at $1{ }^{\circ} \mathrm{C}$ and $90-95 \%$ relative humidity for 8 days before measurements. Four replicate samples of 10 strawberries per cultivar and stage of color development were placed in mesh 1 pint $(0.568 \mathrm{~L})$ baskets and stored on wire racks in a controlled temperature room.

\section{Quality attributes}

Firmness measurements

Firmness ( $3 \mathrm{~mm}$ deformation) was measured at the equatorial part of each strawberry fruit, with an Instron Universal Testing Instrument (model 1132, Instron Corp., Canton, OH, USA). A $50 \mathrm{~kg}$ load cell was used for firmness determination of the fruit. The crosshead speed was $10 \mathrm{~cm} \mathrm{~min}^{-1}$. A $16 \mathrm{~mm}$ diameter convex tip Magness-Taylor type probe was used and data were plotted using a strip recorder at $5 \mathrm{~kg}$ full scale. This test measured individual fruit firmness based on the resistance of the flesh to deformation by the probe. Results in kgf were converted to Newton (N) using the following formula: $\mathrm{N}=\mathrm{kgf} \times 9.8 .^{32}$

\section{Color assessment}

The surface color of each fruit was measured with a hand-held tristimulus reflectance colorimeter (model CR-200b, Minolta Corp., Ramsey, NJ, USA). Color was recorded using the CIE $L^{*} a^{*} b^{*}$ uniform color space (CIE Laboratories), where $L^{*}$ indicates lightness, $a^{*}$ indicates chromaticity on a green $(-)$ to red $(+)$ axis, and $b^{*}$ chromaticity on a blue $(-)$ to yellow (+) axis. Numerical values of $a^{*}$ and $b^{*}$ were converted into hue angle $\left(H^{\mathrm{o}}=\tan -1 b^{*} / a^{*}\right)$ and chroma [Chroma $\left.=\left(a^{*} 2+b^{*} 2\right)^{1 / 2}\right] .{ }^{33}$

\section{Preparation of samples for chemical measurements}

Following firmness and color measurements, four replicate samples of 10 strawberries per cultivar and stage of color development were homogenized in a laboratory blender at high speed for $2 \mathrm{~min}$. The resulting homogenate was either used directly for chemical measurements or first centrifuged at $800 \times g_{n}$ for $30 \mathrm{~min}$ and the resulting supernatant filtered through cheesecloth to obtain a clear juice.

\section{Total soluble phenolics}

Total soluble phenolics (TSP) were measured using the Folin-Ciocalteu reagent. ${ }^{34}$ Aliquots $(0.50 \mathrm{~mL})$ of clear strawberry juice were diluted in $9.5 \mathrm{~mL}$ deionized water, and to $1 \mathrm{~mL}$ of the resulting solution were added $5 \mathrm{~mL}$ of a diluted $(1+9$ deionized water $)$ Folin-Ciocalteu reagent. After $30 \mathrm{~s}$ following addition of Folin-Ciocalteu reagent but before $8 \mathrm{~min}$ had elapsed, $4 \mathrm{~mL}$ of sodium carbonate solution $(0.075 \mathrm{~g}$ of sodium carbonate $\mathrm{mL}^{-1}$ ) were added. After $1 \mathrm{~h}$ at $30^{\circ} \mathrm{C}$ plus $1 \mathrm{~h}$ at $0{ }^{\circ} \mathrm{C}$ the absorbance of the solution was measured at $760 \mathrm{~nm}$. Gallic acid was used as a standard, and the concentration of phenolics was calculated directly from a standard curve since the 
standard and samples were treated identically. Total soluble phenolics were expressed as $\mathrm{mg}$ total soluble phenolics $100 \mathrm{~g}^{-1}$ fruit fresh mass.

\section{Total anthocyanins}

Aliquots $(2.00 \mathrm{~g})$ of the homogenized strawberry samples were dissolved in $18 \mathrm{~mL} 0.5 \%(\mathrm{v} / \mathrm{v}) \mathrm{HCl}$ in methanol and kept at $4{ }^{\circ} \mathrm{C}$ for $1 \mathrm{~h}$, to extract the pigments. The flocculate was filtered off by a single layer of tissue and the absorbance of the resulting clear liquid containing the pigments was measured at $520 \mathrm{~nm}$ (maximum absorbance for anthocyanins). Pigment content was calculated using the following formula: $A b s_{520} \times$ dilution factor $\times$ (molecular weight of pelargonidin $\times$ molar extinction coefficient) where the molecular weight of pelargonidin $=433.2$ and the molar extinction coefficient $=2.908 \times 10^{4}$. Results were expressed as mg pelargonidin $100 \mathrm{~g}^{-1}$ fruit fresh mass. ${ }^{10}$

Cyanidin-3-glucoside and pelargonidin-3-glucoside In order to estimate the changes in cyanidin-3glucoside and pelargonidin-3-glucoside, the main pigments of strawberry fruit, ${ }^{35}$ in the field compared with during storage, $25 \mathrm{~g}$ of the homogenate were blended for $2 \mathrm{~min}$ with $25 \mathrm{~mL}$ methanol acidified with $0.5 \% \mathrm{HCl}$, covered and extracted overnight at $4{ }^{\circ} \mathrm{C}$, filtered through cheesecloth without squeezing and then filtered through a $0.45 \mu \mathrm{m}$ membrane filter (Whatman International Ltd, Kent, UK). Separation of strawberry anthocyanins was conducted on a Waters Millipore (Marlborough, MA, USA) HPLC system using the Millennium 2010 Software Package. A $20 \mu \mathrm{L}$ sample was injected onto a Phenomenex (Torrance, CA., USA) bond clone $10 \mathrm{C}_{18}$ reversephase column $(300 \mathrm{~mm} \times 3.9 \mathrm{~mm})$. The anthocyanins were eluted using a gradient program using a mobile phase of $4.25 \%(\mathrm{v} / \mathrm{v})$ acetone and $11.11 \%(\mathrm{v} / \mathrm{v})$ formic acid $88 \%$ in HPLC-grade water, filtered through a $0.45 \mu \mathrm{m}$ nylon membrane (Whatman International Ltd, Kent, UK) and sparged before use, using a flow rate of $1.5 \mathrm{~mL} \mathrm{~min}^{-1}$. A Waters Model 486 tunable absorbance UV detector was used and the eluate was monitored at $520 \mathrm{~nm}$. Cyanidin-3-glucoside and pelargonidin-3-glucoside were identified by their respective retention times, which averaged 24.8 and $29.1 \mathrm{~min}$, respectively based on their relative elution order, compared with data collected from the literature..$^{35,36}$ Therefore, the first major peak to elute was cyanidin-3-glucoside and the second major peak was pelargonidin-3-glucoside. The concentration of the pigments present in the fruit was estimated using the peak area (ie higher peak area corresponding to higher pigment concentration) and the data were expressed as area units $10^{-3}$.

Soluble solids content, $p H$ and total titratable acidity The soluble solids content (SCB) of the juice samples was determined with an Abbé refractometer and was expressed in terms of fresh weight. The $\mathrm{pH}$ of the juice samples was determined using a $\mathrm{pH}$ meter (model 140, Corning Medical and Scientific Instruments, Medfield, MA, USA) that had previously been standardized to $\mathrm{pH} 4$ and 7 . For total titratable acidity (TTA) measurement, aliquots $(6.00 \mathrm{~g})$ of juice were diluted with $100 \mathrm{~mL}$ distilled water and the titratable acidity determined by titration with $0.1 \mathrm{~mol} \mathrm{~L}^{-1}$ $\mathrm{NaOH}$ to an end point of $\mathrm{pH}=8.1$ with an automatic titrimeter (Fisher Scientific Co., Pittsburg, PA, USA). The results were converted to percentage citric acid $\left[\left(\mathrm{mLNaOH} \times 0.1 \mathrm{~mol} \mathrm{~L}^{-1} \times 0.064 \mathrm{meq} 6.00 \mathrm{~g}^{-1}\right.\right.$ of juice) $\times 100$ ], and expressed in terms of fresh weight.

\section{Total ascorbic acid}

For total ascorbic acid (TAA) analysis, a $5 \mathrm{~g}$ subsample of homogenized fruit tissue from each of the four, ten-berry samples per treatment was combined with $100 \mathrm{~mL}$ of a mixture of $6 \%$ metaphosphoric acid in $2 \mathrm{~mol} \mathrm{~L}^{-1}$ acetic acid. The fruit-acid mixtures were centrifuged for $20 \mathrm{~min}$ at $5000 \times g_{n}$. The analysis was performed by the dinitrophenylhydrazine method of Terada et al. ${ }^{37}$. The concentration of TAA was calculated per $100 \mathrm{~g}$ of fresh weight tissue from absorbance measured at $540 \mathrm{~nm}$ using a standard curve.

\section{Statistical analysis}

A completely randomized design was used. The treatments were a $2 \times 4 \times 3 \times 4$ factorial arrangement of two storage times (before and after storage), four stages of color development (showing color, one-half and three-quarters colored and full red) applied to three cultivars $\times$ four replications of ten strawberries. The Statistical Analysis System computer package was used for analysis of data. ${ }^{38}$ Data were analyzed by analysis of variance (ANOVA) and significant differences between storage treatments and maturities were detected using Duncan's multiple range test (DMRT) and least significant difference (LSD) at $5 \%$ level of significance.

\section{RESULTS AND DISCUSSION \\ Firmness}

Overall, strawberry firmness decreased either during ripening in the field or during storage, regardless of the initial ripeness of the fruit (Fig 1). When ripened in the field, FRC strawberries were softer than less ripe fruit. Strawberries harvested at CB, HC or TQC color stages were 39, 25 and 10\% firmer, respectively, than those harvested at the FRC stage. Previous workers have also reported that the at-harvest firmness of halfred strawberries was $20 \%$ higher than the firmness of full red or dark red strawberries. ${ }^{14,30}$ Ménager et al. ${ }^{30}$ in a study using strawberries from the white to the dark red stages, reported that firmness of the fruit decreased from white to half-red and then appeared to hold steady from three-quarters to full and dark red. In fact, in the present study, the firmness of 'Chandler' and 'Sweet Charlie' strawberries harvested fully red did not 


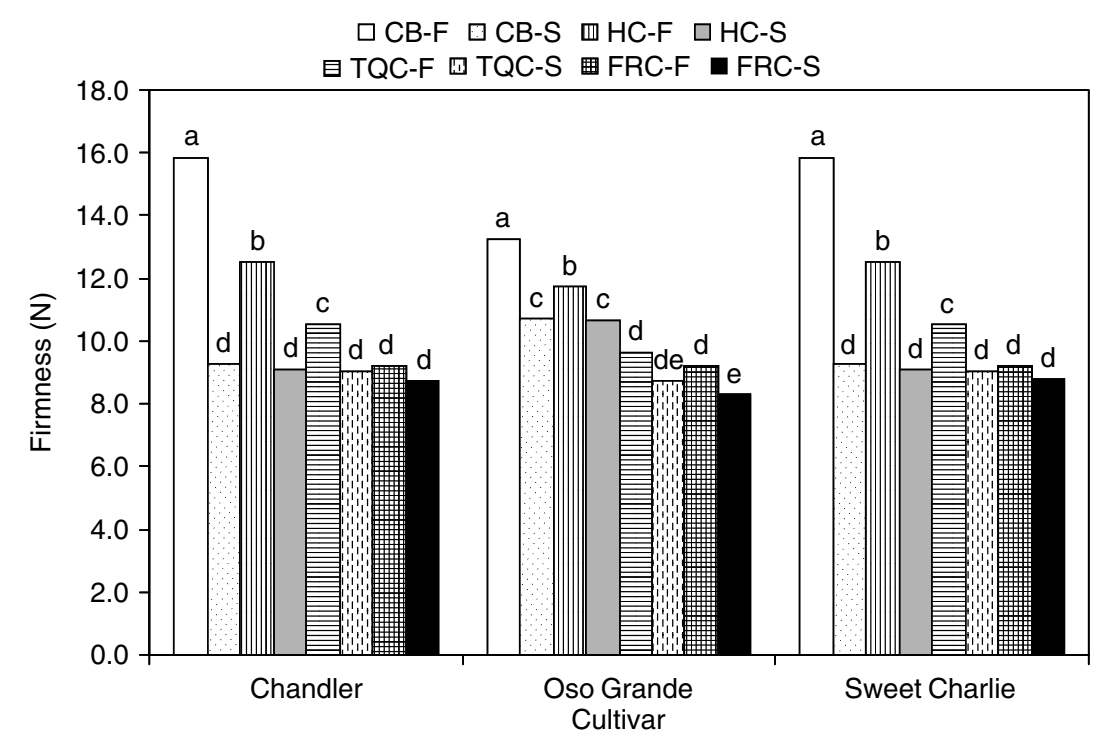

Figure 1. Changes in the firmness of three strawberry cultivars during development in the field and during 8 days storage at $1^{\circ} \mathrm{C}$. $\mathrm{CB}-\mathrm{F}=$ color break fruit in the field; $\mathrm{CB}-\mathrm{S}=$ color break fruit after 8 days of storage; $\mathrm{HC}-\mathrm{F}=$ one-half colored fruit in the field; $\mathrm{HC}-\mathrm{S}=$ one-half colored fruit after 8 days of storage; TQC-F = three-quarter-colored fruit in the field; TQC-S $=$ three-quarter colored fruit after 8 days of storage; FRC-F = full colored fruit in the field; FRC-S = full colored fruit after 8 days of storage. Results are presented as means based on four independent replicate samples of 10 fruit each. Means marked by different letters are significantly different $(P<0.05)$.

change during storage, even though the fruit appeared to be more ripe. Furthermore, there was no significant difference in the firmness of 'Chandler' and 'Sweet Charlie' strawberries after 8 days of storage, regardless of the color stage at harvest. At the time of harvest, $\mathrm{CB}$ and HC 'Oso Grande' strawberries were softer than the fruit from the two other cultivars harvested at the same stages. However, after storage they were firmer than 'Chandler' and 'Sweet Charlie' fruit. Softening of strawberry fruit, either during ripening in the field or during storage is mainly due to loss of cell wall material, which is more pronounced in the cortical tissue than in the pith tissue. ${ }^{27}$ Besides, the extreme fragility of strawberry fruit is due to their particular structure, characterized by large cells and thin cell walls. ${ }^{39}$ Strawberry softening is thought to be primarily due to the presence of polygalacturonase, which solubilizes and degrades the cell wall polyuronides; the soluble polyuronide level is much higher in ripe fruit than in unripe fruit. ${ }^{40,41}$ Overall, firmness of strawberries harvested either $\mathrm{HC}$ or TQC and stored for 8 days at $1{ }^{\circ} \mathrm{C}$ was not significantly different from the firmness of the FRC fruit ripened on the plant.

\section{Color}

The $L^{*}$ value of the strawberries decreased during storage, meaning that the fruit developed darker color, regardless of the maturity at harvest (Fig 2). After 8 days at $1^{\circ} \mathrm{C}$, the $L^{*}$ values of $\mathrm{CB}$ and $\mathrm{HC}$ strawberries were higher (lighter color) than the $L^{*}$ values of FRC strawberries at the time of harvest. The $L^{*}$ values of TQC strawberries after storage were lower (darker color) or not different than those of FRC fruit ripened in the field. Overall, the $L^{*}$ value tended to decrease either during development in the field or during storage, as a consequence of the pinkreddish color that naturally develops when strawberry fruit ripen. As in the present study, decreases in the $L^{*}$ value of strawberry fruit from light green to threequarters red and from white to one-half red have previously been reported by others. ${ }^{24,30}$

The superficial red color of the strawberry fruit as measured by $a^{*}$ value increased during development in the field and during storage, regardless of the cultivar or color stage (Fig 2). Increases in $a^{*}$ values were, however, greater in the $\mathrm{CB}$ and $\mathrm{HC}$ fruit than in the other color stages. Other workers have also showed that $a^{*}$ values increase rapidly in strawberries from the light green to three-quarters red and from the onehalf to three-quarters red stages. ${ }^{24,30}$ In the present study, although values of $a^{*}$ increased 2- to 3-fold in CB strawberries during storage, they never reached the values of TQR or FRC strawberries at the time of harvest. After storage, HC 'Chandler' and 'Oso Grande' strawberries were still 30 and $50 \%$ less red (lower $a^{*}$ value), respectively, than FRC strawberries at the time of harvest. However, 'Sweet Charlie' fruit harvested at HC were only $13 \%$ less red after storage than FRC fruit at the time of harvest. Such results suggest that 'Sweet Charlie', even when harvested at early stages of color development, might be capable of developing full red color faster than the two other cultivars. Overall, $a^{*}$ value after storage of strawberries harvested TQC was not significantly different from that of FRC fruit at the time of harvest.

The hue angle of the strawberries decreased significantly (ie red color developed) during storage regardless of the cultivar or color stage (Fig 2). The largest decrease in the hue was observed in fruit harvested at the $\mathrm{CB}$ or $\mathrm{HC}$ stages, while those harvested at TQC or FRC showed smaller decreases. 


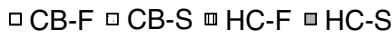

घ TQC-F $\square$ TQC-S $\rightarrow F R C-F$ \#RC-S

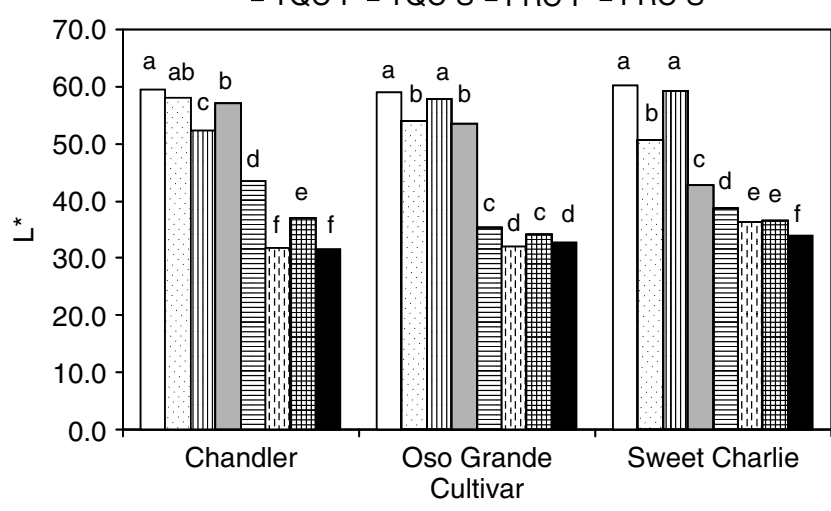

$\square \mathrm{CB}-\mathrm{F} \square \mathrm{CB}-\mathrm{S} \square \mathrm{HC}-\mathrm{F} \square \mathrm{HC}-\mathrm{S}$

घ TQC-F $\square T Q C-S$ $\rightarrow F R C-F \backsim F R C-S$

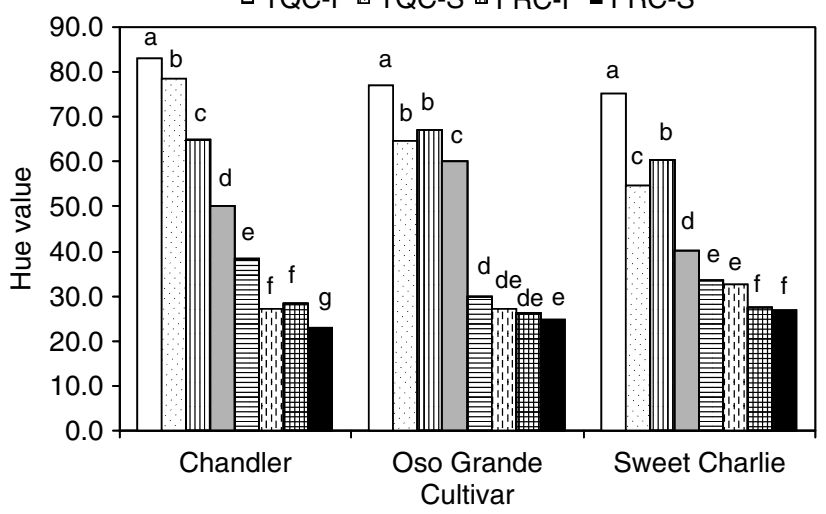

$\square \mathrm{CB}-\mathrm{F} \square \mathrm{CB}-\mathrm{S} \square \mathrm{HC}-\mathrm{F} \square \mathrm{HC}-\mathrm{S}$

$\because T Q C-F \square T Q C-S \otimes F R C-F \backsim F R C-S$

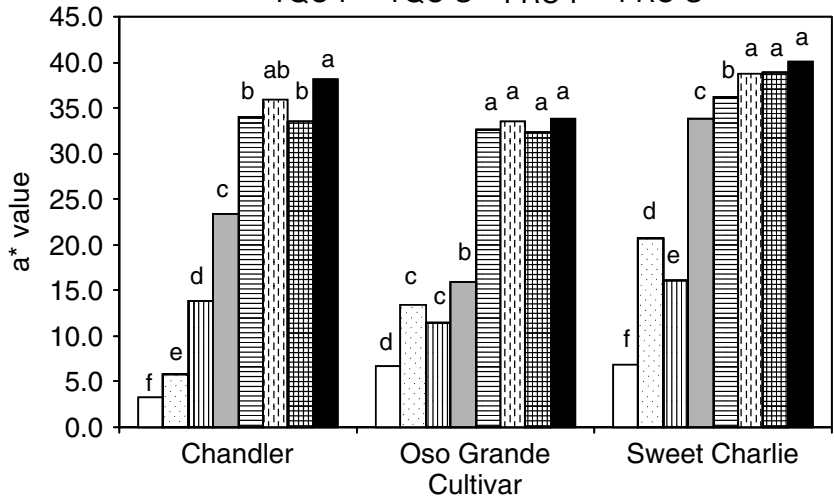

$\square$ CB-F $\square$ CB-S $\square \mathrm{HC}-\mathrm{F} \square \mathrm{HC}-\mathrm{S}$

$\because \mathrm{TQC}-\mathrm{F} \square \mathrm{TQC}-\mathrm{S}$ 由 FRC-F $\square \mathrm{FRC}-\mathrm{S}$

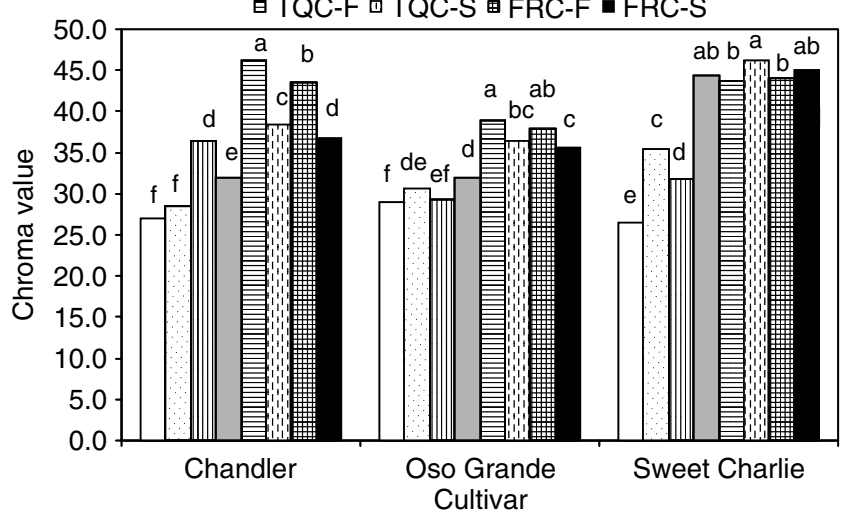

Figure 2. Changes in the $L^{*}, a^{*}$, hue and chroma values of three strawberry cultivars during development in the field and during 8 days storage at $1^{\circ} \mathrm{C}$. CB-F = color break fruit in the field; $\mathrm{CB}-\mathrm{S}=$ color break fruit after 8 days of storage; $\mathrm{HC}-\mathrm{F}=$ one-half colored fruit in the field;

$\mathrm{HC}-\mathrm{S}=$ one-half colored fruit after 8 days of storage; TQC-F = three-quarter-colored fruit in the field; TQC-S = three-quarter colored fruit after

8 days of storage; FRC-F = full colored fruit in the field; FRC-S = full colored fruit after 8 days of storage. Results are presented as means based on four independent replicate samples of ten fruit each. Means marked by different letters are significantly different $(P<0.05)$.

This difference between the color stages illustrates that the $\mathrm{CB}$ and $\mathrm{HC}$ fruit changed from white or light pink to red during storage, while the TQC and FRC fruit were already red. Ménager et al. ${ }^{30}$ also reported that hue angle decreases from white to one-half red fruit and then remains steady as the fruit ripening progresses further. The after-storage hue of 'Chandler' and 'Oso Grande' fruit harvested TQC was similar to that of FRC strawberries at the time of harvest; however, the hue of 'Sweet Charlie strawberries harvested TQR did not change significantly during storage, compared with the hue value at harvest.

During development in the field, the chroma of the strawberries tended to increase from the $\mathrm{CB}$ to the TQC stage and then decrease or hold steady through the FRC stage. Ihl et al. ${ }^{24}$ also reported an increase in the chroma of 'Pajaro' strawberries from the light green to the three-quarters red stage during development in the field. After storage, the higher chroma values observed in riper fruit compared with less ripe fruit indicated that the red color of strawberries was more pure or vivid in the TQC and FRC fruit than in the $\mathrm{CB}$ and $\mathrm{HC}$ fruit (Fig 2). In the TQC and FRC 'Chandler' and 'Oso Grande' strawberries, the chroma decreased during storage, which corresponded to the development of a red-brownish color. In 'Sweet Charlie' strawberries, however, the chroma increased during storage, regardless of the maturity stage.

Perkins-Veazie and Huber ${ }^{42}$ reported that strawberry fruit ripen from white to red color stages in 5-10 days in the field, depending on air temperature, and Ménager et al. ${ }^{30}$ reported that strawberries progress from the half red to the three-quarters red stage within 2-3 days on the plant. In the present study, changes in $L^{*}, a^{*}$, hue and chroma values indicate that strawberry surface color shifted from pinkish-red (TQC) to red during 8 days of storage at $1{ }^{\circ} \mathrm{C}$. Although the color of strawberries harvested at the earlier stages of maturity (ie CB and $\mathrm{HC}$ ) changed during storage, resulting in fruit with increased brightness and red color intensity, the color never reached the same intensity as TQC or FRC strawberries. Previous studies also showed that strawberries change color postharvest, even when harvested at early stages of development. For example, Sacks and Shaw ${ }^{12}$ observed that strawberry fruit darken during storage, and Miszczak et al. ${ }^{13}$ reported that strawberry lightness ( $L^{*}$ value) decreases after harvest in pink and white strawberries. In another study using strawberries harvested partially colored, Austin et al. ${ }^{7}$ 
showed that the fruit could develop red color during storage. In addition, the same authors reported that the development of red color is greatly influenced by temperature as strawberries colored completely in 2 or 4 days at 29 or $24^{\circ} \mathrm{C}$, respectively, and $90 \%$ of full red color developed after 4 days at $18^{\circ} \mathrm{C}$. However, at $13^{\circ} \mathrm{C}$ good color development did not occur. Smith and Heinze ${ }^{6}$ reported that showing color, onehalf, and three-quarters colored strawberries stored at $21^{\circ} \mathrm{C}$ were able to develop full red color in about 4,3 and 2 days, respectively. However, Kalt et al. ${ }^{11}$ observed that red color development in white strawberries held at 5 or $10^{\circ} \mathrm{C}$ was still incomplete after 8 days of storage. In a recent study using strawberries harvested from white to red color stages, Miszczak et al. ${ }^{13}$ reported that, when held at $15^{\circ} \mathrm{C}$ after harvest, pink and white strawberries develop full red color after 4 and 6 days, respectively, and at $20^{\circ} \mathrm{C}$ color development was greater than at $10^{\circ} \mathrm{C}$. In the present study, the color of strawberries harvested $\mathrm{HC}$ and TQC became closer to the color of the fruit harvested at TQC and FRC, respectively, after 8 days at $1{ }^{\circ} \mathrm{C}$. Thus, the degree of color development seems to be dependent on storage time and temperature..$^{6,7,11,13}$ In the present study, the storage temperature $\left(1^{\circ} \mathrm{C}\right)$ used might have delayed red color development. However, if placed on a retail display at $20^{\circ} \mathrm{C}$, the TQC strawberries would probably develop acceptable red color within 1 day.

\section{Chemical composition}

When strawberries were ripened in the field, the TSP content generally decreased from the $\mathrm{CB}$ stage to the TQC stage and increased at the FRC stage (Fig 3). Spayd and Morris ${ }^{22}$ reported a decrease in phenolics content during 'Cardinal' strawberry fruit development. During storage, however, the TSP content of strawberries did not show a consistent trend. The TSP content of 'Chandler' decreased during storage except in the TQC strawberries, in which no changes were observed. The TSP content of 'Oso Grande' increased during storage of $\mathrm{CB}$ and TQC fruit, but decreased or remained the same in HC and FRC fruit, respectively. Finally, the TSP content of 'Sweet Charlie' decreased during storage of $\mathrm{CB}$ strawberries, but increased in fruit from the other color stages. A mean increase of about $16 \%$ in the TSP content was observed from TQC stage to FRC stage in strawberries ripened in the field, while for TQC strawberries ripened during storage the increase was about $0.2 \%$ in 'Chandler', $17 \%$ in 'Oso Grande' and $9 \%$ in 'Sweet Charlie. 'Oso Grande' was, therefore,
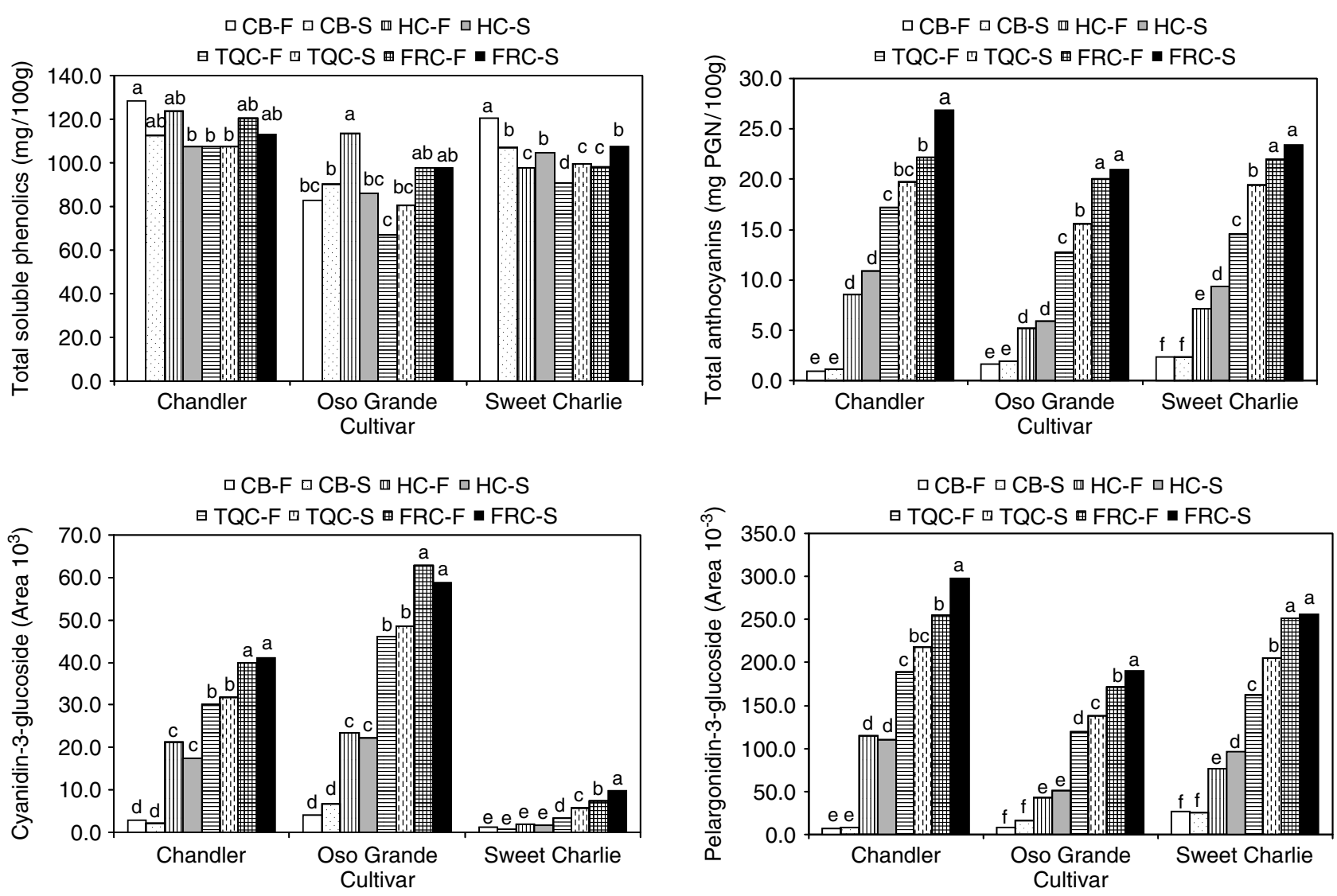

Figure 3. Changes in the total soluble phenolics, anthocyanins, cyanidin-3-glucoside and pelargonidin-3-glucoside of three strawberry cultivars during development in the field and during 8 days storage at $1^{\circ} \mathrm{C}$. CB-F $=$ color break fruit in the field; CB-S $=$ color break fruit after 8 days of storage; $\mathrm{HC}-\mathrm{F}=$ one-half colored fruit in the field; $\mathrm{HC}-\mathrm{S}=$ one-half colored fruit after 8 days of storage; TQC-F $=$ three-quarter-colored fruit in the field; TQC-S = three-quarter colored fruit after 8 days of storage; FRC-F = full colored fruit in the field; FRC-S = full colored fruit after 8 days of storage. Results are presented as means based on four independent replicate samples of ten fruit each. Means marked by different letters are significantly different $(P<0.05)$. 
the only cultivar that showed an increase close to that observed in field-ripened strawberries. The increase in TSP content of strawberries after the FRC stage might be related to the development of a dark red-brownish color as observed in this study as well as previously in fully red or overripe strawberries in addition to the accumulation of anthocyanins during ripening in the field or during storage (see below). ${ }^{23,43}$

There was a significant increase in the total anthocyanins (TA) content of strawberries ripened in the field or during storage, regardless of the initial color stage (Fig 3). As in the present study, Cordenunsi et $a l .{ }^{26}$ reported an increase in the anthocyanin content of 'Oso Grande' strawberries ripened in the field, from the full-size 'white turning red' stage to the full-size three-quarters red stage. Several other authors have reported that, as strawberry fruit ripen on the plant, the anthocyanin content increases, while the chlorophyll content declines. ${ }^{15,23,29,44}$ The TA content of CB fruit did not change significantly during storage. Similarly, no significant changes were observed in the TA content of HC fruit, with the exclusion of 'Sweet Charlie', in which the TA content increased. While the TA content of FRC fruit either increased or did not change significantly, the TA content of TQC strawberries increased significantly during storage. However, the increase in TA content of TQC fruit during storage was much lower than that which occurred in the field. A mean increase of about $31 \%$ in the TA content was observed from TQC to FRC for strawberries ripened in the field, while for TQC strawberries ripened during storage the increase was about $13 \%$ in 'Chandler', $18 \%$ in 'Oso Grande' and $25 \%$ in 'Sweet Charlie'. 'Sweet Charlie' was, therefore, the only cultivar that showed an increase in TA content close to that observed in field-ripened strawberries. These results suggest that, when strawberries are harvested at early stages of maturity, they probably do not have the capacity to synthesize a large amount of anthocyanins during storage at low temperatures, while fully red fruit might show either a reduced synthesis or increased degradation of anthocyanins. Cordenunsi et al. ${ }^{17}$ reported that the anthocyanin content of 'Oso Grande' strawberries harvested at the full-size three-quarters red stage increased after 3 days at 6,16 or $25^{\circ} \mathrm{C}$ and suggested that anthocyanin biosynthesis is delayed at lower storage temperatures. In another study, Kalt et al. ${ }^{16}$ similarly reported that the anthocyanin content of fully red 'Kent' strawberries increased 1.7 -fold during 8 days of storage at $0^{\circ} \mathrm{C}$ while for the same period at $30^{\circ} \mathrm{C}$ the increase was 6.8 -fold. Therefore, it is possible that the TQC fruit used in our study might have been able to develop a full red color comparable to that of FRC strawberries ripened in the field if the storage temperature was higher than $1^{\circ} \mathrm{C}$. However, one should consider that accelerated senescence and development of decay and thus reduction of strawberry shelf life might also result if strawberry fruit are stored at temperatures higher than $1^{\circ} \mathrm{C} .{ }^{45-47}$
Cyanidin-3-glucoside is responsible for the red color and pelargonidin-3-glucoside is responsible for the orange-brown color in strawberries. ${ }^{48}$ Both pigments increased significantly from the CB stage to the FRC stage in fruit ripened in the field (Fig 3). Kosar et al $^{29}$ also reported increases in both cyanidin3-glucoside and pelargonidin-3-glucoside in several strawberry genotypes during ripening on the plant. TQC 'Oso Grande' strawberries showed the lowest concentration of pelargonidin-3-glucoside at harvest followed by 'Sweet Charlie' and 'Chandler'. The higher content of cyanidin-3-glucoside and the lower content of pelargonidin-3-glucoside in 'Oso Grande' confirm the visual observation of a more deep-red fruit at the fully red stage compared with the two other cultivars, which showed a more orange-reddish color. Wrolstad et $a l .{ }^{49}$ reported previously that the different proportions of those two pigments affect the color of different strawberry varieties.

Although no significant changes were observed in the cyanidin-3-glucoside content of 'Chandler' and 'Oso Grande' strawberries during storage regardless of the maturity stage, TQC and FRC 'Sweet Charlie' strawberries showed a slight increase in cyanidin-3-glucoside content. The concentration of pelargonidin-3-glucoside in the $\mathrm{CB}$ fruit did not increase significantly during storage, and in $\mathrm{HC}$ fruit an increase in the pigment was observed only in 'Sweet Charlie'. However, the pigment significantly increased in TQC fruit during storage. One of the most important factors to promote anthocyanin synthesis is light, ${ }^{50}$ and in the present study the fruit were stored in the dark, which might have contributed to the reduced synthesis of these pigments.

Mean increases of about $28 \%$ in the cyanidin3 -glucoside content and $30 \%$ in the pelargonidin3-glucoside content were observed from the TQC stage to the FRC stage in strawberries ripened in the field. The increases in cyanidin-3-glucoside for TQC strawberries ripened during storage were $6 \%$ in 'Chandler', 5\% in 'Oso Grande' and $41 \%$ in 'Sweet Charlie', while for pelargonidin-3-glucoside the increases were $13 \%$ in 'Chandler' and 'Oso Grande', and $21 \%$ in 'Sweet Charlie. 'Sweet Charlie' was, therefore, the only cultivar that showed increases in cyanidin-3-glucoside and pelargonidin-3-glucoside during storage like that observed in field-ripened strawberries.

Moing et al. ${ }^{25}$ reported that the $\mathrm{pH}$ was close to 5 in strawberries at 10 days after full bloom, decreased to 3.7 at the turning stage and then remained unchanged through full ripeness; however, in previous studies it has been reported that the $\mathrm{pH}$ of the fruit increases as strawberry fruit mature. ${ }^{15,22}$ Montero et al. ${ }^{23}$ also reported an increase in strawberry $\mathrm{pH}$ after 21 days from fruit set. In the present study, the $\mathrm{pH}$ of strawberries in the field increased significantly as the fruit ripened (Fig 4). Overall, when ripened during storage, the $\mathrm{pH}$ of the strawberries did not change significantly from that at the time of harvest, regardless 

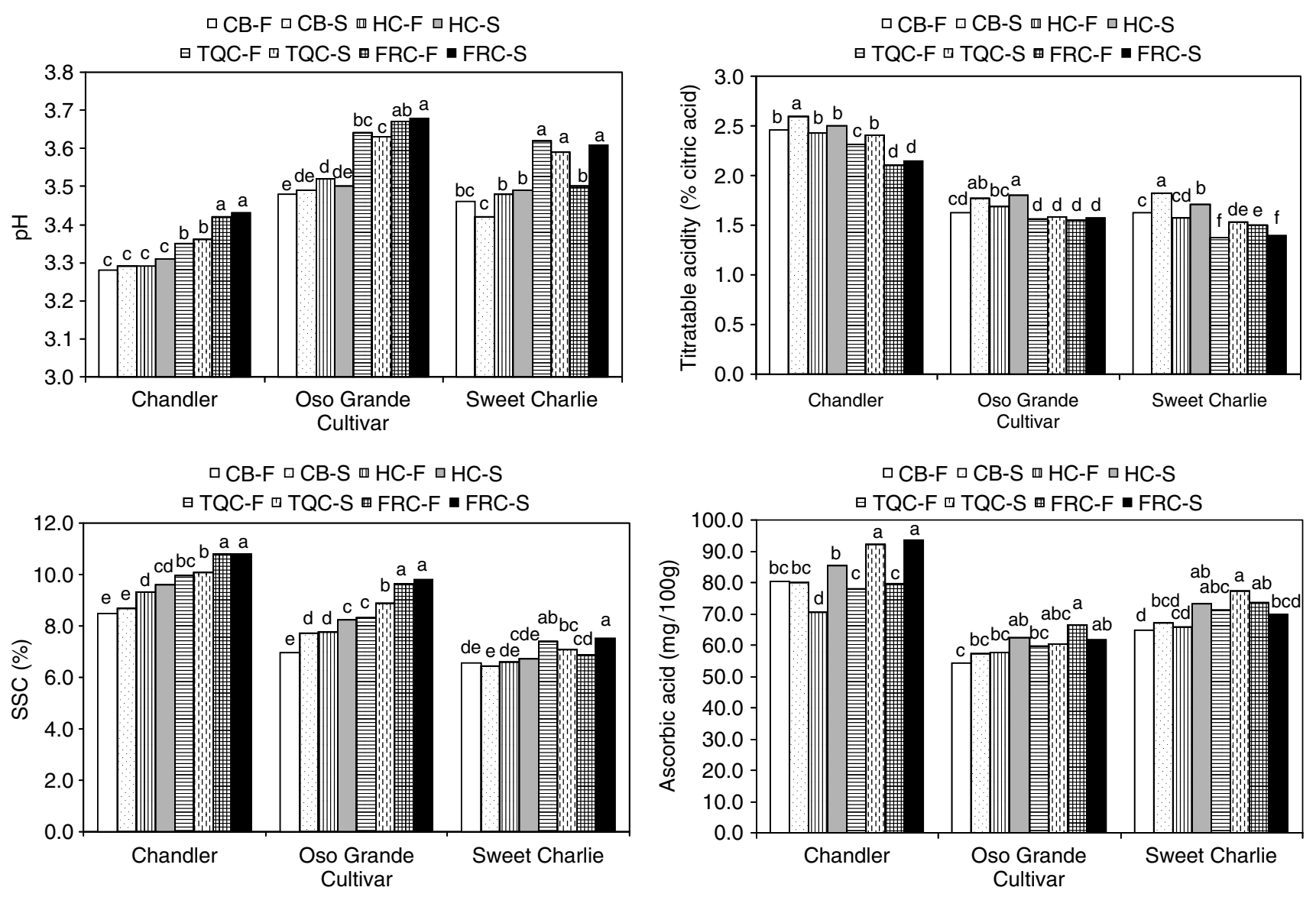

Figure 4. Changes in the $\mathrm{pH}$, titratable acidity, soluble solids and total ascorbic acid content of three strawberry cultivars during development in the field and during 8 days storage at $1^{\circ} \mathrm{C}$. CB-F = color break fruit in the field; $\mathrm{CB}-\mathrm{S}=$ color break fruit after 8 days of storage; $\mathrm{HC}-\mathrm{F}=$ one-half colored fruit in the field; HC-S = one-half colored fruit after 8 days of storage; TQC-F = three-quarter-colored fruit in the field;

TQC-S = three-quarter colored fruit after 8 days of storage; FRC-F = full colored fruit in the field; FRC-S = full colored fruit after 8 days of storage. Results are presented as means based on four independent replicate samples of ten fruit each. Means marked by different letters are significantly different $(P<0.05)$.

of the initial color stage of the fruit. Although Olsson et al. ${ }^{19}$ reported a decrease in the $\mathrm{pH}$ content of ripe dark red strawberries after 3 days at $4{ }^{\circ} \mathrm{C}$, it is possible that in the present study the low temperature used to store the fruit might have contributed to a stabilization of the $\mathrm{pH}$ of the fruit throughout storage.

The TTA of CB, HC and TQC strawberries expressed in terms of citric acid equivalents, one of the major acids in strawberry, ${ }^{23}$ tended to increase during storage (Fig 4). Fruit harvested at TQC had almost the same TTA after storage as FRC strawberries at the time of harvest. Although the TTA of the strawberries increased during storage, the same was not observed in field-ripened strawberries, as those fruit showed a significant decrease in TTA as they ripened. Moing et al. ${ }^{25}$ reported an increase in strawberry juice TTA from 10 days after full bloom to the turning stage (change between white and pink) and then a decrease until the fruit were fully red and suitable for commercial picking. Ménager et al. ${ }^{30}$ showed that the TTA did not differ for white and pink strawberries, but decreased from the one-half red stage to the dark red stage. Other studies have also reported that the more mature or ripe the strawberry, the lower its acid content. ${ }^{6,11,15,22,23}$
The SSC of 'Oso Grande' increased by 10, 6.5 and $7 \%$ during storage at $1{ }^{\circ} \mathrm{C}$ in fruit harvested at the $\mathrm{CB}$, $\mathrm{HC}$ and TQC stages, respectively (Fig 4). Likewise, the SSC of 'Chandler' fruit harvested at the FRC stage increased by $9 \%$ during storage. Cordenunsi et al. ${ }^{17}$ reported an increase of up to $30 \%$ in the total soluble sugars of full-size, three-quarters red 'Oso Grande' strawberries during storage at $6^{\circ} \mathrm{C}$ for 6 days; however, there were no significant changes during storage in the SSC of 'Chandler' and 'Sweet Charlie' strawberries harvested before the FRC stage. Although Reyes et al. ${ }^{51}$ observed a decline in SSC in overripe strawberries, in this study the SSC of the FRC 'Sweet Charlie' strawberries remained practically the same or increased during storage. Overall, after 8 days at $1{ }^{\circ} \mathrm{C}$, the SSC of $\mathrm{HC}$ and TQC strawberries was only 10 and 5\% lower, respectively, than that of FRC fruit at the time of harvest. In an early study, Austin et al. ${ }^{7}$ reported that the SSC of strawberries harvested green to pink and ripened in the dark compared favorably to the SSC of field-ripened strawberries. In this study, like in other previous works, ${ }^{22,23,30}$ strawberries in the field became richer in SSC as they ripened. Postharvest increases in SSC are probably not due to conversion of starch to soluble sugars since 
strawberry fruit accumulate very little starch during development. ${ }^{52}$ The increase in TTA noted above, however, undoubtedly contributed to the increase in SSC since acids contribute to the SSC. Increased SSC during storage of FRC fruit might also be explained by solubilization of cell wall polyuronides and hemicelluloses. ${ }^{40,41}$

The TAA content of strawberries varied depending on the cultivar (Fig 4). 'Chandler' had the highest TAA content at the time of harvest, regardless of the color stage of the fruit. Furthermore, at the end of storage the TAA content of 'Chandler' harvested at HC, TQC or FRC stages increased by $21.5,18.5$ and $17.7 \%$, respectively, while the TAA content of HC 'Sweet Charlie' increased by $11.5 \%$. Cordenunsi et $a l .{ }^{17}$ reported a $10 \%$ increase in the TAA acid of full-size, three-quarters red 'Oso Grande' strawberries after storage at $16^{\circ} \mathrm{C}$ and attributed the increase to the synthesis of ascorbic acid during storage. Olsson et al. ${ }^{19}$ also reported an increase in the ascorbic acid content of strawberries during storage for 2 days at $4{ }^{\circ} \mathrm{C}$. In fact, it has been suggested that increases in TAA content during storage of fruits and vegetables might be attributed to the synthesis of ascorbic acid from monosaccharides, since in plants most synthesis starts with pre-formed Dglucose. A non-inversion pathway for ascorbic acid synthesis from D-glucose in higher plants has been suggested, in which the C-1 of glucose becomes the $\mathrm{C}-1$ of L-ascorbic acid. The process involves oxidation of C-1 and C-2 from glucose and epimerization of C-5, while the hydroxymethyl group at C-6 is conserved. ${ }^{53-55}$ Therefore, the increase in the TAA content of strawberries during storage might be attributed to a possible synthesis of ascorbic acid from D-glucose, a sugar normally encountered in strawberry fruit. ${ }^{51}$ Overall, after 8 days at $1{ }^{\circ} \mathrm{C}$ the TAA content of HC and TQC strawberries was 0.7 and 5\% higher than that of FRC strawberries at the time of harvest. Ascorbic acid content of fruit ripened in the field increased as the fruit matured, with the most significant increases in the TAA content observed from the HC stage to the FTC stage in 'Chandler' and from the TQC stage to the FRC stage in 'Oso Grande'. Other authors have also reported increases in TAA content of strawberries during development and ripening. ${ }^{22,23,26}$

\section{CONCLUSIONS}

Strawberries harvested at different developmental stages continued their development during storage, but only the more advanced TQC and FRC fruit exhibited changes consistent with ripening. Strawberries harvested at the earlier CB and HC stages did not develop like those ripened in the field. Consequently, only strawberries harvested at the TQC and FRC stages will continue ripening in storage. Overall, strawberries harvested at the TQC stage developed $\mathrm{pH}$, acidity, SSC, TAA and TSP contents during storage for 8 days at $1{ }^{\circ} \mathrm{C}$ that were similar to those of FRC strawberries. Total anthocyanin, cyanidin-3-glucoside and pelargonidin-3-glucoside content were much lower in all stored fruit compared with field-ripened fruit, probably due to the low storage temperature and lack of light. Furthermore, TQC strawberries can be as firm and red after storage as those harvested at the FRC stage. After storage, FRC strawberries were less firm than fruit harvested at earlier stages of color development and developed a very dark color. 'Sweet Charlie' was the only cultivar that showed an increase in TAA as well as in cyanidin-3-glucoside and pelargonidin-3-glucoside during storage like that observed in strawberries ripened in the field. Also, 'Oso Grande' was the only cultivar that showed a postharvest increase in TSP close to that observed in field-ripened strawberries. Strawberries harvested TQC continue to develop normally during storage and, besides, they can be stored for a longer period without losing their red color and firmness. While these observations are consistent with a climactericripening pattern, strawberry respiration and ethylene production are known to follow a non-climacteric pattern.

\section{ACKNOWLEDGEMENTS}

Authors express their gratitude to Dr Charles Sims of the Food Science and Human Nutrition Department at the University of Florida for his helpful and valuable comments and suggestions and for the use of his laboratory. We also thank Mr Al Herndon of Ferris Farms, Floral City, Florida for his cooperation in conducting this research. This research was supported by a grant to MCN Nunes from JNICT (Junta Nacional de Investigação Científica e Tecnológica), Portugal.

\section{REFERENCES}

1 Biale JB and Young RE, Respiration and ripening in fruitretrospect and prospect, in Recent Advances in the Biochemistry of Fruits and Vegetables, ed by Friend J, Rhodes MJC. Academic Press, London, pp. 1-39 (1981).

2 Perkins-Veazie PM, Huber DJ and Brecht JK, In vitro growth and ripening of strawberry fruit in the presence of ACC, STS or propylene. Ann Appl Biol 128:105-116 (1996).

3 Luo Y and Liu X, Effects of ethylene on RNA metabolism in strawberry fruit after harvest. F Hortic Sci 69:137-139 (1994).

4 Wills RBH and Kim GH, Effect of ethylene on postharvest life of strawberries. Postharv Biol Technol 6:249-255 (1995).

5 Bower JH, Biasi WV and Mitcham EJ, Effects of ethylene and 1MCP on the quality and storage life of strawberries. Postharv Biol Technol 28:417-423 (2003).

6 Smith WL Jr and Heinze PH, Effect of color development at harvest on quality of post-harvest ripened strawberries. $\mathcal{F} \mathrm{Am}$ Soc Hortic Sci 72:207-211 (1958).

7 Austin ME, Shutak VG and Christopher EP, Color changes in harvested strawberry fruit. $\mathcal{F}$ Am Soc Hortic Sci 75:382-386 (1960).

8 Atta-Aly MA, Brecht JK and Huber DJ, Ethylene feedback mechanisms in tomato and strawberry fruit tissues in relation 
to fruit ripening and climacteric patterns. Postharv Biol Technol 20:151-162 (2000).

9 McGlasson WB, Ethylene and fruit ripening. HortScience 20:51-54 (1985).

10 Spayd SE and Morris JR, Effects of immature fruit and holding on strawberry puree and color stability. F Am Soc Hortic Sci 106:211-216 (1981).

11 Kalt W, Prange RK and Lidster PD, Postharvest color development of strawberries influence of maturity, temperature and light. Can F Plant Sci 73:541-548 (1993).

12 Sacks EJ and Shaw DV, Color change in fresh strawberry fruit of seven genotypes stored at $0{ }^{\circ} \mathrm{C}$. HortScience 28:209-210 (1993).

13 Miszczak A, Forney CF and Prange RK, Development of aroma volatiles and color during postharvest ripening of 'Kent' strawberries. F Am Soc Hortic Sci 120:650-655 (1995).

14 Forney CF, Kalt W, McDonald JE and Jordan MA, Changes in strawberry fruit quality during ripening and off the plant. Acta Hortic 464:506 (1998).

15 Woodward JR, Physical and chemical changes in developing strawberry fruits. $\mathcal{F}$ Sci Food Agric 23:465-473 (1972).

16 Kalt W, Forney CF, Marti A and Prior RL, Antioxidant capacity, vitamin $\mathrm{C}$, phenolics and anthocyanins after storage of small fruit. $\mathcal{F}$ Agric Food Chem 47:4638-4644 (1999).

17 Cordenunsi BR, Genovese MI, Nascimento JRO, Hassimotto NMA, Santos RJ and Lajolo FM, Effects of temperature on the chemical composition and antioxidant activity of three strawberry cultivars. Food Chem 91:113-121 (2005).

18 Ayala-Zavala JF, Wang SW, Wang CY and González-Aguilar GA, Effect of storage temperatures on antioxidant capacity and aroma compounds in strawberry fruit. Lebensm Wiss Technol 37:687-695 (2004).

19 Olsson ME, Ekvall J, Gustavsson KE， Nilsson J, Pillai D, Sjöholm I, Svensson U, Åkesson B and Nyman MGL, Antioxidants, low molecular weight carbohydrates, and total antioxidant capacity in strawberries (Fragaria $\times$ ananassa): effects of cultivar, ripening, and storage. $\mathcal{f}$ Agric Food Chem 52:2490-2498 (2004).

20 Neal GE, Changes occurring in the cell walls of strawberries during ripening. I Sci Food Agric 16:604-611 (1965).

21 Spayd SE and Morris JR, Physical and chemical characteristics of pure from once-over harvested strawberries. F $\mathrm{Am}$ Soc Hortic Sci 106:101-105 (1981).

22 Spayd SE and Morris JR, Changes in strawberry quality during maturation. Ark Farm Res 30:6-6 (1981).

23 Montero TM, Mollá EM, Esteban RM and López-Andréu FJ, Quality attributes of strawberry during ripening. Sci Hortic 65:239-250 (1996).

24 Ihl M, Martín AS and Bifani V, Preliminary report on colour quality measured as chlorophyllase activity in strawberries at different stages of maturity. Acta Hortic 485:181 - 185 (1999).

25 Moing A, Renaud C, Gaudillère M, Raymond P, Roudeillac P and Denoyes-Rothan B, Biochemical changes during fruit development of four strawberry cultivars. F Am Soc Hortic Sci 126:394-403 (2001).

26 Cordenunsi BR, Nascimento JRO, Genovese MI and Lajolo FM, Influence of cultivar on quality parameters and chemical composition of strawberry fruits grown in Brazil. $\mathcal{F}$ Agric Food Chem 50:2581-2586 (2002)

$27 \mathrm{Koh} \mathrm{TH}$ and Melton LD, Ripening-related changes in cell wall polysaccharides of strawberry cortical and pith tissues. Postharv Biol Technol 26:23-33 (2004).

28 Strum K, Koron D and Stampar F, The composition of fruity of different strawberry varieties depending on maturity satge. Food Chem 83:417-422 (2003).

29 Kosar M, Kafkas E, Paydas S and Baser KHC, Phenolic composition of strawberry genotypes at different maturation stages. F Agric Food Chem 52:1586-1598 (2004).

30 Ménager I, Jost $M$ and Aubert C, Changes in physicochemical characteristics and volatile constituents of strawberry (cv. Cigaline) during maturation. 7 Agric Food Chem 52:1248-1254 (2004).

31 Maynard DN and Hochmuth GJ, Sherman M, Strawberry Production Guide for Florida. Florida Cooperative Extension Service, IFAS, University of Florida, Gainesville, FL, circular no $142 \mathrm{C}$ (1988).

32 Kader AA, Proper units for firmness and abscission force data. HortScience 17:707-707 (1982).

33 Francis FJ, Color quality evaluation of horticultural crops. HortScience 15:58-59 (1980).

34 Singleton VL and Rossi JA, Colorimetry of total phenolics with phosphomolybdic-phosphotungistic acid reagents. Am $\mathcal{F}$ Enol Vitic 16:144-157 (1965).

35 Bakker J, Bridle P and Koopman A, Strawberry juice color: the effect of some processing variables on the stability of anthocyanins. $\mathcal{F}$ Sci Food Agric 60:471-476 (1992).

36 Lopes-da-Silva F, Pascual-Teresa S, Rivas-Gonzalo J and Santos-Buelga C, Identification of anthocyanin pigments in strawberry (cv Camarosa) by LC using DAD and ESI-MS detection. Eur Food Res Technol 214:248-253 (2002)

37 Terada M, Watanabe Y, Kunitomo $M$ and Hayashi E, Differential rapid analysis of ascorbic acid 2-sulfate by dinitrophenylhydrazine method. Anal Biochem 84:604-608 (1978).

38 SAS Institute Inc. SAS User's Guide: Statistics. SAS Institute, Carey, NC (1982).

39 Szczesniak AS and Smith BJ, Observations on strawberry texture a three-pronged approach. F Text Studies 1:65-89 (1969).

40 Huber DJ, Strawberry fruit softening: the potential roles of polyuronides and hemicelluloses. F Food Sci 49:1310-1315 (1984).

41 Nogata Y, Ohta H and Voragen AGV, Polygalacturonase in strawberry fruit. Phytochemistry 34:617-620 (1993).

42 Perkins-Veazie PM and Huber DJ, Growth and ripening of strawberry fruit under field conditions. Proc Fla State Hortic Soc 100:253-256 (1987).

43 Nunes MCN, Brecht JK, Morais AMMB and Sargent SA, Physical and chemical quality characteristics of strawberries after storage are reduced by a short delay to cooling. Postharv Biol Technol 6:17-28 (1995).

44 Given NK, Venis MA and Grierson D, Phenylalanine ammonialyase activity and anthocyanin synthesis in ripening strawberry fruit. F Plant Physiol 133:25-30 (1988).

45 Nunes MCN, Brecht JK, Morais AMM and Sargent SA, Controlling temperature and water loss to maintain ascorbic acid levels in strawberries during postharvest handling. F Food Sci 63:1033-1036 (1998).

46 Nunes MCN and Emond JP, Quality of strawberries after storage in constant or fluctuating temperatures, in Proceedings of the 20th International Congress of Refrigeration, Sydney, paper no 205 (1999).

47 Nunes MCN, Emond JP and Brecht JK, Quality of strawberries as affected by temperature abuse during ground, in-flight and retail handling operations. Acta Hortic 604:239-246 (2003).

48 Bakker J, Bridle P and Bellworthy SJ, Strawberry juice colour: a study of the quantitative and qualitative pigment composition of juices from 39 genotypes. I Sci Food Agric 64:31-37 (1994).

49 Wrolstad RE, Putnam TP and Varseveld GW, Color quality of frozen strawberries: effect of anthocyanin, $\mathrm{pH}$, total acidity and ascorbic acid variability. F Food Sci 35:448-452 (1970).

50 Gross J, Anthocyanins, in Pigments in Fruit, Food Science and Technology; ed by Schweigert BS. Academic Press, New York, pp. 59-85 (1987).

51 Reyes FGR, Wrolstad RE and Cornwell CJ, Comparison of enzymic, gas-liquid chromatographic, and high performance liquid chromatographic methods for determining sugars and 
organic acids in strawberries at three stages of maturity. $\mathcal{F}$ Assoc Offic Anal Chem 65:126-131 (1982).

52 Souleyre EJF, Iannetta PPM, Ross HA, Hancock RD, Shepherd LVT, Viola R, Taylor MA and Davies HV, Starch metabolism in developing strawberry (Fragaria $\times$ ananassa) fruits. Physiol Plant 121:369-376 (2004).

53 Liao $M$ and Seib P, Chemistry of L-ascorbic acid related to foods. Food Chem 30:289-312 (1988).
54 Loewus FA and Loewus MW, Biosynthesis and metabolism of ascorbic acid in plants. CRC Crit Rev Plant Sci 5:101-119 (1987).

55 Seib PA and Tolbert BM, Ascorbic Acid: Chemistry, Metabolism, and Uses. Advances in Chemistry Series 200. American Chemistry Society, Washington, DC (1982). 